\title{
Patient dying on ECMO support? "It's not the circulation that's the problem, it's the liver, stupid!"
}

\author{
Michel Carrier, MD, MBA
}

\author{
From the Department of Surgery, University of Montreal, Montreal, Quebec, Canada. \\ Disclosures: Author has nothing to disclose with regard to commercial support. \\ Received for publication Jan 27, 2017; accepted for publication Feb 4, 2017; available ahead of print March 7, \\ 2017. \\ Address for reprints: Michel Carrier, MD, MBA, Montreal Heart Institute, 5000 Belanger St, Montreal, Quebec, \\ Canada H1T 1C8 (E-mail: michel.carrier@icm-mhi.org). \\ J Thorac Cardiovasc Surg 2017;153:1373 \\ $0022-5223 / \$ 36.00$ \\ Copyright (C) 2017 by The American Association for Thoracic Surgery \\ http://dx.doi.org/10.1016/j.jtcvs.2017.02.002
}

The long-time accepted strategies to support the systemic circulation when the heart fails have reached new frontiers with the use of ventricular assist devices (VADs), total artificial hearts (TAHs), and the recent explosion in the number of patients supported by extracorporeal membrane oxygenation (ECMO). Patients with acute cardiac failure and cardiogenic shock of varying etiologies are now offered mechanical circulatory support. Of course, if and when resolution of the initial insult occurs, the patient will nicely recover and will be weaned off mechanical support. When recovery fails, a decision to move toward a long-term VAD approach (including the TAH) or directly to transplantation soon becomes imperative.

In the current issue of the Journal, Hoefer et $\mathrm{al}^{1}$ suggest that measurements of activity levels of antithrombin III below $60 \%$, at the onset of ECMO support is associated with the development of acute and irreversible liver failure (ALF), regardless of the success of the circulatory support in place. They report that $45(27 \%)$ of 164 patients developed ALF while on venoarterial ECMO according to the King's College criteria for the diagnosis of ALF. Hospital mortality reached almost $90 \%$ in the group of patients with ALF compared with 35\% mortality in patients on mechanical circulatory support who remained free from ALF.

The authors used the MELD score ${ }^{2,3}$ (model for endstage liver disease) calculated by measuring total bilirubin, serum creatinine, and international normalized ratio. This score is used to predict survival in patients with end-stage liver disease. A MELD score greater than 17 before mechanical support was associated with ALF with a sensitivity of $89 \%$, a specificity of $93 \%$, and a positive predictive value of $83 \%$.

The authors stress that the levels of antithrombin III produced by hepatocytes is a powerful indicator of the metabolic functional reserve of the liver and that a reduction in antithrombin III activity is strongly associated with upcoming liver failure. The authors conclude that both a high MELD score and decreased antithrombin III activity

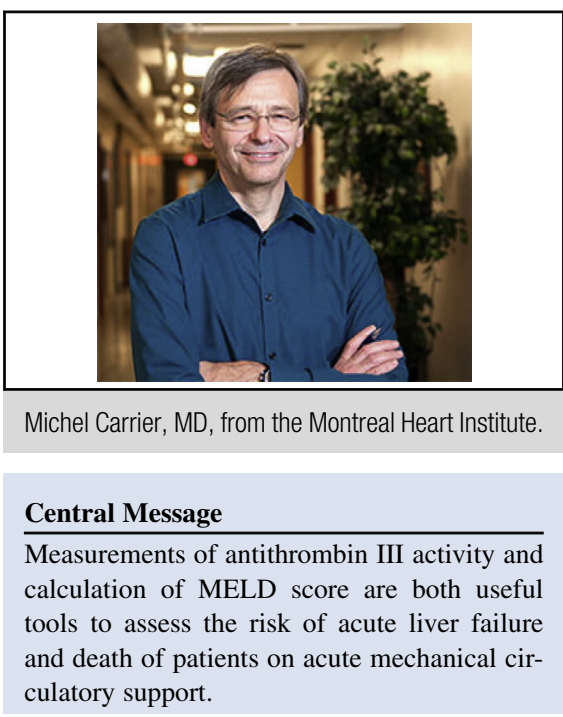

See Article page 1374 .

levels are strongly associated with ALF and mortality in patients undergoing mechanical support for cardiac failure and cardiogenic shock.

Results from Hoefer et al $^{1}$ should be carefully evaluated. Levels of antithrombin III activity and the MELD score can be helpful in the decision process to undergo bridge to bridge with a long-term VAD or to go directly to urgent heart transplantation. At risk here are the costs associated with long-term VAD, the appropriate use of a limited pool of organ donors in transplantation, and the survival rate of the mechanically supported patients. ${ }^{4}$ Levels of antithrombin III activity and the MELD score will remain, in my mind, highly useful tools to help the decision process. In the end, the take-home message is that it's the liver that determines (at least in part) the success or failure in these complex patients.

\section{References}

1. Hoefer J, Ulmer H, Kilo J, Margreiter R, Grimm M, Mair P, et al. Antithrombin III is associated with acute liver failure in patients with end-stage heart failure undergoing mechanical circulatory support. J Thorac Cardiovasc Surg. 2017;153:1374-82.

2. Kamath P, Weisner M, Malinchoc M. A model to predict survival in patients with end-stage liver disease. Hepatology. 2001;33:464-70.

3. Freeman RB, Weisner RH, Harper A, McDiamid SV, Lake J, Edwards E, et al. The new liver allocation system: moving toward evidence-based transplantation policy. Liver Transpl. 2002;8:851-8.

4. Withman GJR. Extracorporeal membrane oxygenation for the treatment of postcardiotomy shock. J Thorac Cardiovasc Surg. 2017;153:95-101. 